\title{
Design for accessibility for floating structures
}

\author{
Matthew East BEng (Hons1), MIEAust \\ Maritime and Coastal Service Line Coordinator, GHD Pty Ltd, Cheadle, UK \\ (corresponding author: matthew.east@ghd.com) \\ (Orcid:0000-0002-2938-5528)
}

\begin{abstract}
This paper focuses on recent works completed by GHD Pty Ltd in 2016 for the design of accessible ferry terminals and looks at the techniques utilised and designs implemented to develop terminals with the intent to provide inclusive unassisted all-tide access. To achieve this, the design looked at the pontoon and gangway (brow) configuration and ways to achieve compliant slopes, along with the engagement of an access consultant and workshops with a sample of the user group. The works also focused on lessons and research from previous designs, the use of visual aids, including three-dimensional walkthrough models and virtual reality goggles to present the design to the client and user group, and design solutions required to achieve the necessary compliance. This paper provides a summary of these key findings regarding accessible slopes, design tide ranges, terminal orientation, sight lines, provision of landing and rest areas, dedicated waiting areas, lighting, walkway width and ergonomics.
\end{abstract}

\section{Introduction}

Recently, many transport infrastructure operators have been undertaking works to improve access to public transport facilities for mobility-impaired patrons. These works have focused on step-free access from vehicle (train, bus or car) to kerb for on-land infrastructure.

However, floating structures, such as ferry terminals, are one of the more complex infrastructure designs, impacted by pontoon movements and tidal variations. Owing to the dynamic movements of floating structures, they pose a significant challenge to achieving compliance with the design code of practice for access for mobility-impaired patrons.

Figures provided by the UK government (MHCLG, 2014) indicate that in 2014/2015 there were approximately 11 million people with limiting long-term illness, impairment or disabilities. The prevalence of disability is reported to increase with age, and can be broken down into the following age groups

- $6 \%$ of the population of children are disabled

- $16 \%$ of working age adults are disabled

- $45 \%$ of adults over state pension age are disabled.

According to the Institute for Employment Studies (Meager et al., 1999), the estimated spending power of this select group of patrons is $£ 51.3$ billion to the UK economy, not including the benefits of providing access to work or facilities for many within this group (MHCLG, 2014).

Of this significant group of patrons, around a fifth have reported difficulties in utilising public transport and result in utilising other forms of transport or limit their travels to known areas.
The UK has an ageing population and the percentage of patrons with mobility impairments is set to increase dramatically over the next few decades. Over the next 40 years, it is possible that the UK's entire population will only increase by $7 \%$; however, the number of people over 65 is set to rise by $40 \%$.

It is not only disabled people who benefit from accessible design. Of the current population, there are a further 18 million people that can be classed as older persons, parents with children under the age of five, those recently involved in an accident and friends, relatives or carers who accompany people with disabilities who would directly or indirectly benefit from inclusive access to buildings and public spaces.

Currently, both the Australian and UK standards for design for access and mobility (AS 1428.1 and AS 1428.2 (SA, 1992, 2009) and BS 8300 (BSI, 2009)) provide guidance for buildings and access paths leading to buildings. However, these standards focus on permanent fixed structures. Owing to the dynamic motion and variable levels of pontoons and gangways, it is difficult to apply these requirements to floating structures.

This is further complicated by other conflicting requirements, such as minimum lighting requirements and reducing glare on navigation channels. Therefore, to address these areas of conflict and ambiguity, the design team engaged an access consultant.

\section{User group engagement}

There are many physical and mental impairments that may impede mobility and access. The design of the terminal needed to consider the vast requirements for a significant portion of the patrons that may utilise the facilities, including those in 
wheelchairs, those with sight impairment, the elderly, those who utilise mobility devices, patrons with motor neurone diseases and parents with prams.

Compliance with codes and acts is only one element of the provision of transport infrastructure. Behavioural influences, functionality and safety are further considerations to achieving fair and equitable use of ferry infrastructure and maximising the social and economic performance of the investment (Lovelace, 2015).

Given the range of users for which the design needed to consider and assist, the constraints imposed by the environment and to gain a first-hand understanding of users' requirements, engagement of the community was sought through an access consultant. Discussions with end users led to an understading of what currently works, what needs to be improved, elements of the code that are considered minimum requirements and those identified as desirable requirements. The consultation with the user group consisted of workshops, facilitated by the access consultant, research of current negative and positive feedback of current installed facilities (both on land and floating) and a review of international practices.

Other elements discussed with the user group were the walkway width, the design and location of the handrails and kick rails, and lighting to the structure.

Results of the user group engagement are discussed further in the following sections of this paper, with the results influencing the overall design presented.

\section{Design requirements}

The works referred to in this paper were completed for public transport facilities along the Brisbane River, Australia, with design spanning from 2000 to the present. As such, the designs were completed in accordance with the Australian Disability Discrimination Act 1992 (Australian Government, 2014), and the Disability Standards for Accessible Public Transport (DSAPT) (Australian Government, 2002).

The DSAPT are the standards derived by the Australian Government for the design of public transport facilities in Australia in accordance with the Disability Discrimination Act 1992 .

The document provides requirements and guidance for the design of access paths from the shoreline to the vessel (and vice versa), as well as requirements for lighting of the facility, minimum requirements for floor finishes to achieve a non-slip surface, balustrade heights, handrail heights and configuration, and minimum requirements for signage.
The standard refers the designer to clauses contained in AS 1428.1 (SA, 2009) and AS 1428.2 (SA, 1992), wherein design parameters for each element are provided. This, in particular, covers elements such as access paths, manoeuvring areas, passing areas, resting points, ramps and waiting areas.

\section{Terminal breakdown}

Ferry terminals can be roughly broken down into three elements

(a) on-land land infrastructure/waiting area

(b) gangway (otherwise known as brow or linkspan)

(c) pontoon/waiting area.

These elements are shown in Figure 1.

Typically, older terminals are configured such that the waiting area is located onshore so that patrons may wait on a stable structure that is not exposed to the forces generated during the berthing of vessels and wave motions. Patrons would await the arrival of the vessel and head down the gangway to the pontoon to board after patrons aboard the vessel have disembarked.

The vertical range of the tide means that the slope of the gangway is never constant, changing from a shallow slope to a relatively steep slope, meaning that the construction of ramps and landings complying with code requirements is difficult.

Once on the pontoon, patrons are exposed to a structure that is in continuous motion. The pontoon rolls and pitches due to moving loads, wave and wind actions and horizontal motion from vessel impacts during berthing. This motion of the pontoon can result in instability under foot and nonconforming cross-falls for ramps and stairs if these are included on the pontoon deck.

\section{Gangway - access path slope}

The gangway acts as a connector between the on-land infrastructure, which remains at a fixed height, and the floating infrastructure, which is in continual motion due to variation in tide.

Typically, a gangway is a single ramp with the slope varying depending on the pitching point height, the height of the pontoon and the tide level. However, in most circumstances, the vertical difference between the pitching point and low tide can be quite large, requiring either a long shallow ramp or a short steep ramp. Accessibility codes put limitations on both the slope and length of ramp, to which most typical gangway designs struggle to comply. 

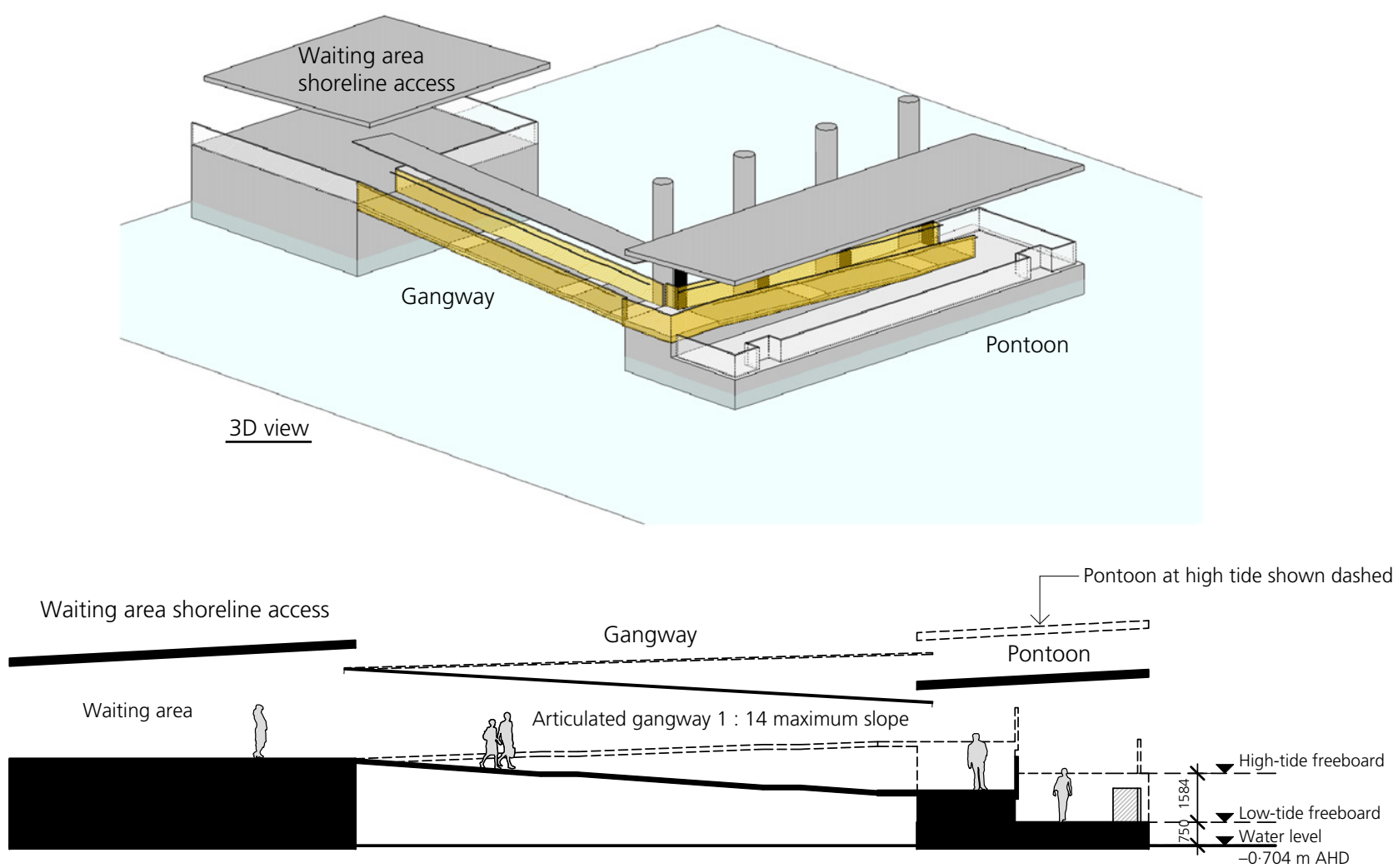

$\underline{\text { Section }}$

Figure 1. Terminal configuration. AHD, Australian height datum

\subsection{Gangway slope types}

Over the timeframe from 2000 to the present there have been four variations to the design of the slope of the gangway.

(a) Design 1 (Initial) - A straight gangway with a maximum slope of $1: 16$, utilising a $U$ truss frame (design $c .2000$ by GHD Pty Ltd) - refer to the gangway shown in Figure 1.

(b) Design 2 - A gangway with an internal articulating walkway that provided a series of $1: 14$ ramps with landings to comply with the accessibility requirements, utilising a box truss frame (design $c$. 2012 by others) refer to the gangway shown in Figure 2.

(c) Design 3 - The provision of a fixed ramp on the pontoon and the use of the same gangway as per $(b)$; however, with a shortened gangway due to the fixed ramp on the pontoon, utilising a box truss frame (design $c .2012$ by others) - refer to the pontoon configuration shown in Figure 3.

(d) Design 4 (Current) - A fixed ramp on the pontoon and a shortened gangway with internal ramp and landings,

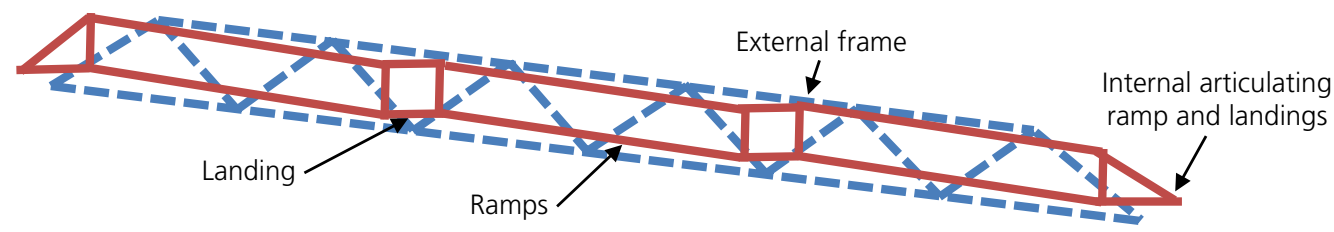

Figure 2. Example of gangway configuration 

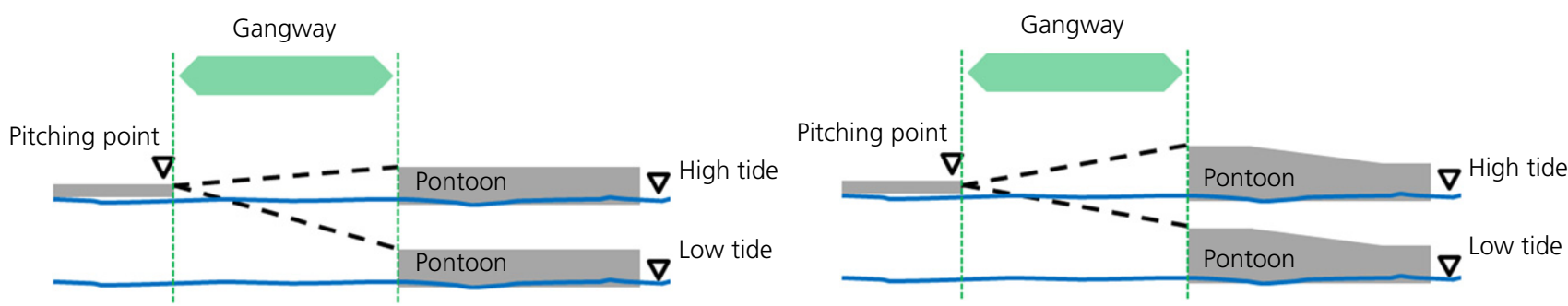

Figure 3. Gangway ramps for various pontoon configurations

utilising a $\mathrm{U}$ truss frame (design $c .2016$ by GHD) - refer to the gangway shown in Figure 2.

In 2000, limited guidance was provided in Australia regarding design for accessibility, similar to the current conditions here in the UK. As such, best practice at the time was used to define the layout of the facility. These structures were discussed in the user group consultation and provided a good reference to what worked well and what needed to be improved. From these designs, each subsequent design thereafter refined the design approach and improved on the innovations defined in the previous works.

The design of the ferry terminals for designs $(b),(c)$ and $(d)$ were completed in accordance with Australian standards and the DSAPT. These codes and the Australian Disability Discrimination Act require the slope of the gangway to be equal to, or less than, 1:14 for short ramps (maximum $6 \mathrm{~m}$ length) or $1: 20$ for long ramps also known as walkways (maximum $19.5 \mathrm{~m}$ length) for $80 \%$ of the tide time. Outside of this time, the slope is to remain less than $1: 8$ in accordance with the marina code (Australian Government, 2002).

\subsection{Benefits and disadvantages of ramps and landings within the gangway}

In theory, the design standards provided three methods for which compliance could be obtained (SA, 1992, 2009)

\footnotetext{
$1: 32$ for a continuous walkway

- $1: 20$ for a $19 \cdot 5 \mathrm{~m}$ long walkway

- $1: 14$ for a $6 \mathrm{~m}$ long walkway.
}

As the slope of the ramp increases, the amount of effort required for a patron to reach the top of the ramp also increases and therefore the length between resting points must be decreased to prevent fatigue.

A ramp with a slope of $1: 32$ would result in a significantly long gangway and was quickly discounted from the design options. Focus was therefore directed to the $1: 14$ and $1: 20$ options.

For the 2016 design of the terminals, the tide range at the project site, including the effects of sea level rise over the design life, was in excess of $1950 \mathrm{~mm}$ and therefore a $1: 20$ gangway without intermediate landings would not comply with the requirements stated within AS 1428.1 (SA, 2009). This meant that a more intricate gangway would be required to achieve compliance with the code or lenience would need to be sought.

From the user group consultation, anecdotal and observational experience showed that a relatively small variation in slope can significantly affect a user's ability to traverse a slope independently (Lovelace, 2015).

For example, at a kerb ramp, a 1:9.5 slope is more functional and useable than the compliant $1: 8$ slope as the foot rests on a wheelchair can impact with the initial start of the ramp, causing a loss of momentum. Further to this, the user group consultation found that not all patrons can use a $1: 14$ slope independently but a $1: 15 \cdot 5$ slope, or shallower, is much more functional for a greater proportion of the population.

This is not only the case for users of mobility devices such as wheelchairs, but also to ambulatory users who may be slower, have poor balance or are less confident on slopes, such as people who are injured, unwell or ageing.

The question was thus asked, would it be better to provide a gangway with intermediate landings or utilise a shallow gangway with a length that exceeded the allowances of the DSAPT requirements?

A gangway of shallow slope without intermediate landings would provide an unhindered consistent gradient where the main consideration will simply be control of speed. A patron (if walking) would be able to utilise a regular gait pattern from top to bottom, no matter the tide range. 
For most parts of the tide range, the difference between the downward or upward slope and the landing will be limited. For a gangway with intermediate landings, identification of the change in slope between ramp and landing can be difficult for those with visual impairments due to the limited variation. Even a small change can create a trip hazard or stumbling point for users who shuffle, are using crutches or are unable to lift their feet sufficiently.

A gangway with the provision of steeper ramps and landings for resting points creates a potential zone of disruption to the flow of those boarding and disembarking, and a potential congestion point if a patron was to rest on the landings during busy periods. Therefore, provision for a wider gangway would need to be made to minimise potential congestion.

The provision of ramps and landings will generate velocity changes for a wheelchair user as they transition from the steep slope to the flat surface and back to the steeper slope. This would be similar to the experience of permanent ramps constructed on land and was considered only to be a minor issue.

For wheelchair users, steeper gradients promote increased momentum (rolling). It therefore becomes more difficult to control a wheelchair at gradients steeper than $1: 20$, such as $1: 14$. This is true regardless of weather conditions; however, wet weather increases the level of difficulty to brake and control the device, especially given that manual wheelchairs have only a park brake and therefore decreasing rate of travel must be controlled by the person's hands.

In simple terms, to push an object up an incline of $1: 14$ against 1:20 requires around 40\% extra energy. However, a $1: 20$ ramp without landings will be approximately $20-25 \%$ longer than a $1: 14$ ramp with landings. Consider a ramp to be designed for an operating ramp height of $1500 \mathrm{~mm}$.

- A 1:14 ramp with $6 \mathrm{~m}$ long ramps and 1.2 $\mathrm{m}$ long intermediate landings would have a minimum overall length of $24.6 \mathrm{~m}$.

- A 1:20 ramp with no intermediate landings would have a minimum length of $30 \cdot 0 \mathrm{~m}$.

The additional cost of the internal walkway for the $1: 14$ configuration is largely offset by the cost of extending the ramp to achieve the $1: 20$ slope, although additional operational expenditure would need to be allowed for the mechanical elements.

Through consultation with the user group, a maximum length of a gangway at a consistent slope of $1: 20$ was not defined. It was identified that a length of $19.5 \mathrm{~m}$, as stated in AS 1428.1 (SA, 2009a), would be the upper extents of energy a patron may be able to utilise to ascend the slope, although preference for a 1:20 slope without intermediate landings was identified even with the increased length.

The use of intermediate landings for a 1:20 ramp was considered, however the stresses induced in the mechanical bearings for a 1:20 ramp with landings would exceed their capacity. The limitation of the length of the ramps and structural limits led to the decision that the $1: 14$ ramp and landing configuration would be utilised for the design.

\subsection{Ramps and landings}

One key consideration made within the DSAPT is that compliance with the ramp slope and length stated in AS 1428.1 and AS 1428.2 (SA, 1992, 2009) is only sought for $80 \%$ of the tide time range, and then for the remainder of the time to the Australian standard for marina design (AS 3962 (SA, 2001)). The reduction in the tide time frame is understood to be based on an accepted responsibility by the government-owned transport facilities to provide assistance during extreme tides (a deckhand would escort patrons to and from the vessel during extreme tides). An example of the $80 \%$ tide time range is presented in Figure 4 for a sample site. The actual water levels at each site and the determination of the $80 \%$ tide range need to be assessed on a location-by-location basis.

The design of the gangway needed to consider the provision of landings within the length of the gangway that remained flat across all tide ranges. To achieve this, a design was developed that considered the use of an external support frame and an internal articulating ramp and landing configuration. The ramps and landings were designed to be controlled by the rotation of the external frame as the pontoon moves through the tide range, mechanical bearings and the geometry of the internal framing.

From the user group consultation, it was identified that there was a preference to provide a shallower slope than that identified in AS 1428.1. Therefore, rather than designing the internal ramps to be of the minimum length possible, each bay was extended to the maximum ramp length allowable $(6.0 \mathrm{~m})$, extending the gangway by $4 \mathrm{~m}$ beyond the minimum length. Owing to the orientation of the gangway and the fact that the internal articulating ramp was only vertically supported by the external frame, extending the gangway to provide this shallower angle was achieved with minimum impact on the overall cost of the infrastructure.

A series of $6 \mathrm{~m}$ ramps was provided with $1.2 \mathrm{~m}$ long landings in between. A fixed landing was provided with a rigid vertical elements that remain at $90^{\circ}$ to flat; the ramps were then designed as parallelograms. The top and bottom chords are able to rotate about hinge points located within the vertical 


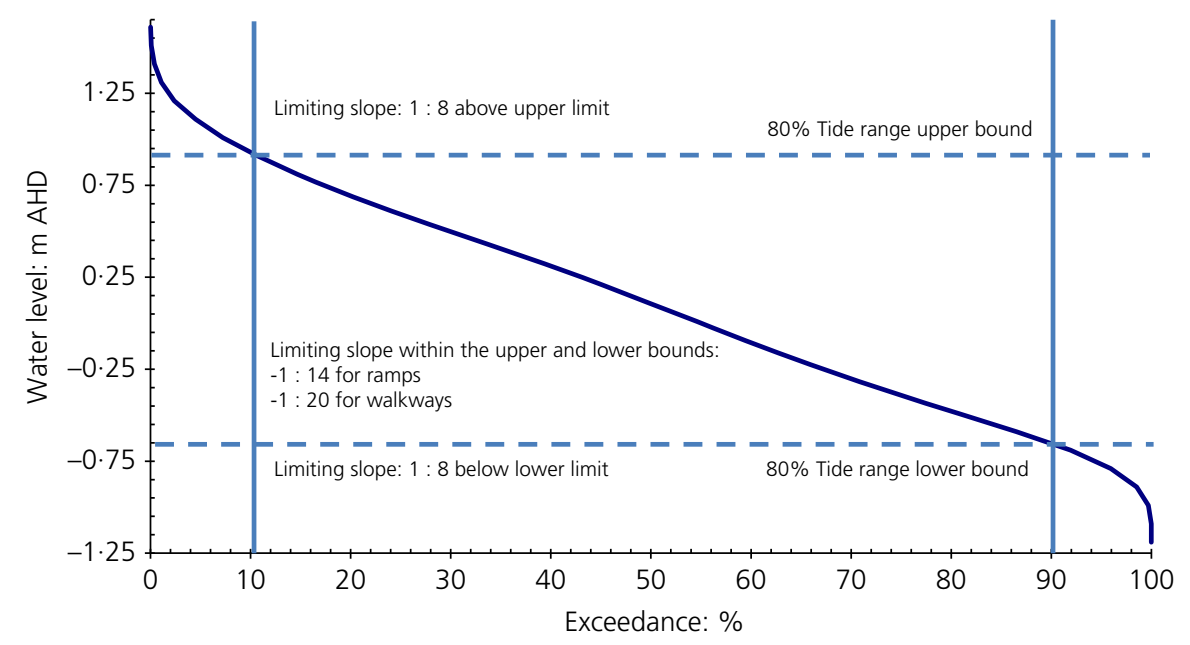

Figure 4. Example of tide range and limiting slopes

element at the fixed landing and the landings are designed as rigid rectangles with hinge points connecting to the top and bottom chord of the ramps. This geometry ensures that the landings will remain horizontal during variations in the tide range, as visually represented in Figure 2.

As the horizontal nature of the landings are controlled by the rigid vertical at the fixed landing, variations in the ramp slope caused by deflection of the external frame can occur without affecting the level of the landing. Therefore, the external structure could be designed with some flexibility as per a typical gangway design, reducing the overall weight of the structure.

Utilising this configuration of the ramps and landings, the gangway could be designed at various lengths to suit all tide ranges and can be extended, if required, to provide shallower slopes to suit the end-user requirements.

\subsection{Gangway vertical movement}

Typically, a gangway would go from the pitching point to the pontoon deck, with the gangway at its steepest slope at the lowest tide and being relatively flat or slightly inclined at the highest tide. This means that the traditional design of the gangway length is dependent on the vertical difference between the pitching point and the height of the pontoon deck at low tide.

To maximise the vertical range of the gangway, a fixed ramp was included on the pontoon (see Figure 3). The ramp on the pontoon was included at a height such that the gangway would be nearly flat at mean sea level, meaning that the gangway was able to rotate upwards and downwards to the upper and lower limits while remaining within the limits of the slopes specified by the code. This in turn meant that the gangway could potentially double its compliant range.

For example, a $1: 20$ gangway with a length of $19 \cdot 5 \mathrm{~m}$ provides $975 \mathrm{~mm}$ of vertical range. If the design of the pontoon was to consider a fixed ramp on the pontoon that enables the gangway to be flat at mean sea level, the maximum vertical operational envelope doubles, becoming $1950 \mathrm{~mm}$.

\subsection{Orientation of the gangway}

One of the other drivers for the terminal design was the provision of flood immunity during extreme events. Typical terminal designs normally have the gangway orientated perpendicular to the river bank. However, with the gangway orientated in this manner it would be susceptible to lateral loads from debris impacts along the gangway's weakest axis, requiring a robust structure (such as an enclosed box truss) to take the impact energy and disperse it to the pontoon and landing. Instead of following a traditional design, the gangway for these terminals was aligned with the flow direction of the flood, such that any forces imparted by flooding would act along the gangway's primary axis.

This orientation also reduces the likelihood of impact as the gangway can be hidden behind the fixed infrastructure or pontoon and the exposed area of the gangway is reduced. If debris were to impact the gangway, it would do so at the angle at which the gangway is inclined, allowing a percentage of the forward momentum to be transferred into downward momentum, further reducing the impact force (Figure 5). 


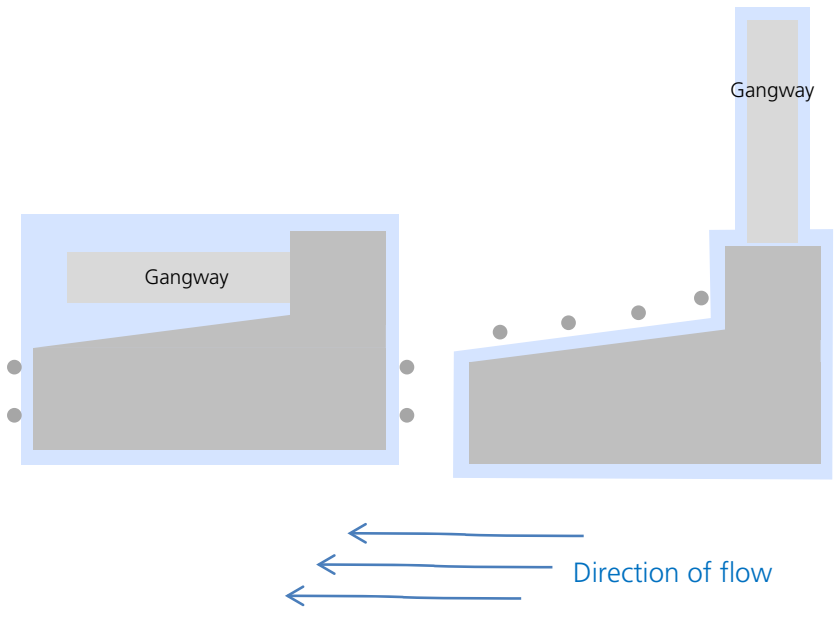

Figure 5. Orientation of pontoon

This allowed the structural form to be reduced, which meant the gangway could be constructed from a $U$ frame truss design, minimising sight line impacts through the terminal. Vision through the terminal was key to the design as it allowed patrons to see approaching vessels and improved security as it minimised locations where people may hide.

From previous works (2012 design), it was found that a gangway perpendicular to the flow of the river that was constructed out of a meshed box truss resulted in a significant loss of sight line from the shore to the pontoon (Figure 6). This resulted in some patrons missing vessels or incorrectly identifying incoming vessels as the ones they required. The loss of sight lines also presented issues concerning the security of the terminal in that segments of the pontoon were obscured from vision from the shore, resulting in an increase in the potential of anti-social behaviour.

Therefore, the provision of a terminal that has clean sight lines throughout allows patrons to identify incoming and disembarking vessels accurately and improves security as more of the terminal can be seen. The ability to see through the terminals also assists the operators because deckhands are able to see the entire pontoon, gangway and landing infrastructure to identify if anybody is in need of assistance.

\subsection{Gangway design summary}

The design of a gangway should consider

- maximising the vertical range of the gangway movement

- the inclusion of ramps and landings within the gangway to improve overall access across greater tide ranges

- orientation of the gangway to the flow of the river

- greater visibility from the land to the water and from the water to the land to improve patrons' ability to recognise incoming vessels and improve visual security.

The study found that a $1: 20$ continuous ramp would provide a better configuration for mobility-impaired patrons. However, without a detailed understanding of the maximum length to which a 1:20 ramp could be extended and the stresses within the structural and mechanical members, a 1:14 ramp with intermediate landings is preferred for design purposes. There is

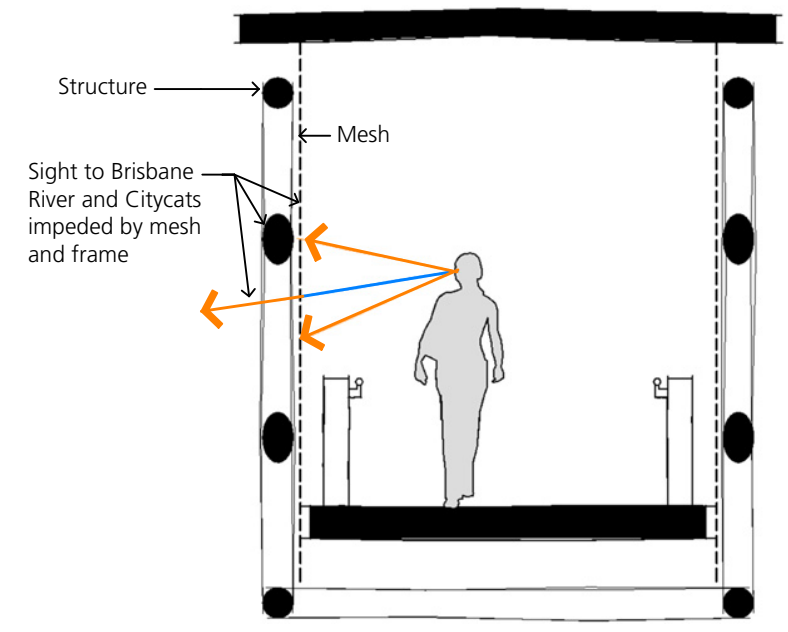

(a)

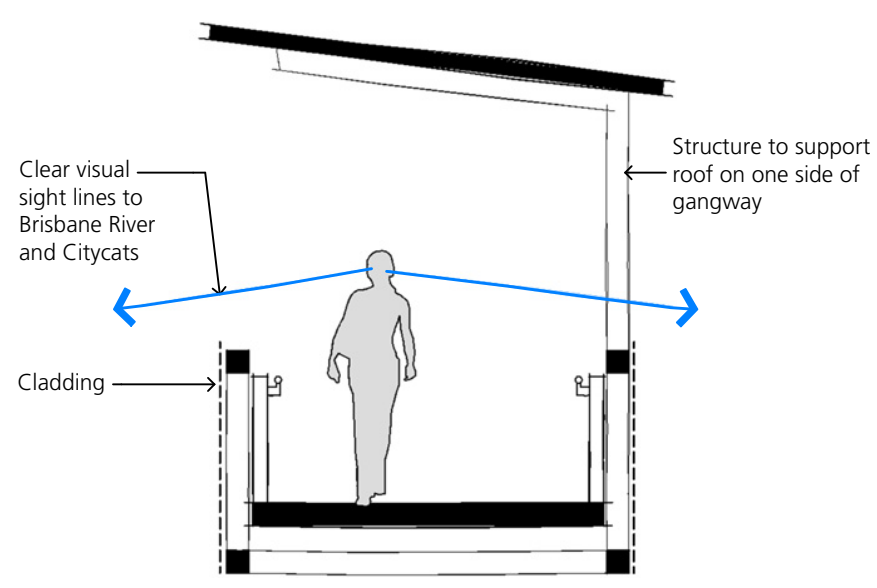

(b)

Figure 6. Sight lines through the gangway: (a) meshed gangway (b) GHD-proposed design 
potential to undertake a further study regarding the maximum lengths a mobility-impaired patron may be able to utilise for a $1: 20$ ramp.

\section{Landings on pontoons}

The review of potential options for the gangway configuration identified that a gangway with landings could generate congestion issues if a patron was to stand on one of the landings.

To minimise this occurrence, a large gangway landing zone should be applied on the pontoon so patrons may congregate within this area without impeding the flow of the terminal (Figure 7). This area can be utilised by those with mobility impairments to gather themselves before heading to shore or for parents with children to gather family members together before disembarking. The landing also provides a suitable area for patrons to wait should congestion have occurred on the gangway.

\section{Waiting areas on pontoons}

The DSAPT state that resting areas should be provided at $60 \mathrm{~m}$ intervals along an access path (Australian Government, 2002). Similarly, the UK government advises that a rest area should be provided every $100 \mathrm{~m}$ for those with mobility impairments who do not need the assistance of a walking aid and every $50 \mathrm{~m}$ for those with sticks (DfT, 2013).
One of the key concerns raised by the user group was that the additional length of the gangways to achieve the slope requirements spread out the rest points; therefore, a rest area was required to be provided at the start and finish of the gangway.

The user group also highlighted that the time taken to get from shore to vessel would be extended, thus increasing the risk of the mobility-impaired patrons missing their vessel. For instance, some terminals are located up to $100 \mathrm{~m}$ away from the shoreline and the waiting area. Most vessels arrive at the terminal, disembark passengers, board and leave within a 5 min window.

It was found, that under current circumstances, patrons make their way down to the pontoon before the arrival of the vessel and rest against the hand railing. Most existing pontoons are only designed to provide enough space to allow patrons to either disembark or board the vessel; therefore, the presence of patrons, particularly those using a walking aid, wheelchair or pram, waiting for their vessel would constrain the flow of the access path. The impact on the terminal flow would be further increased if the patrons were awaiting the arrival of the next vessel; for instance if a downstream bound vessel arrived, but they were awaiting an upstream service.

The smaller size of the existing pontoons also meant that motions from waves and vessel impacts caused the pontoon to

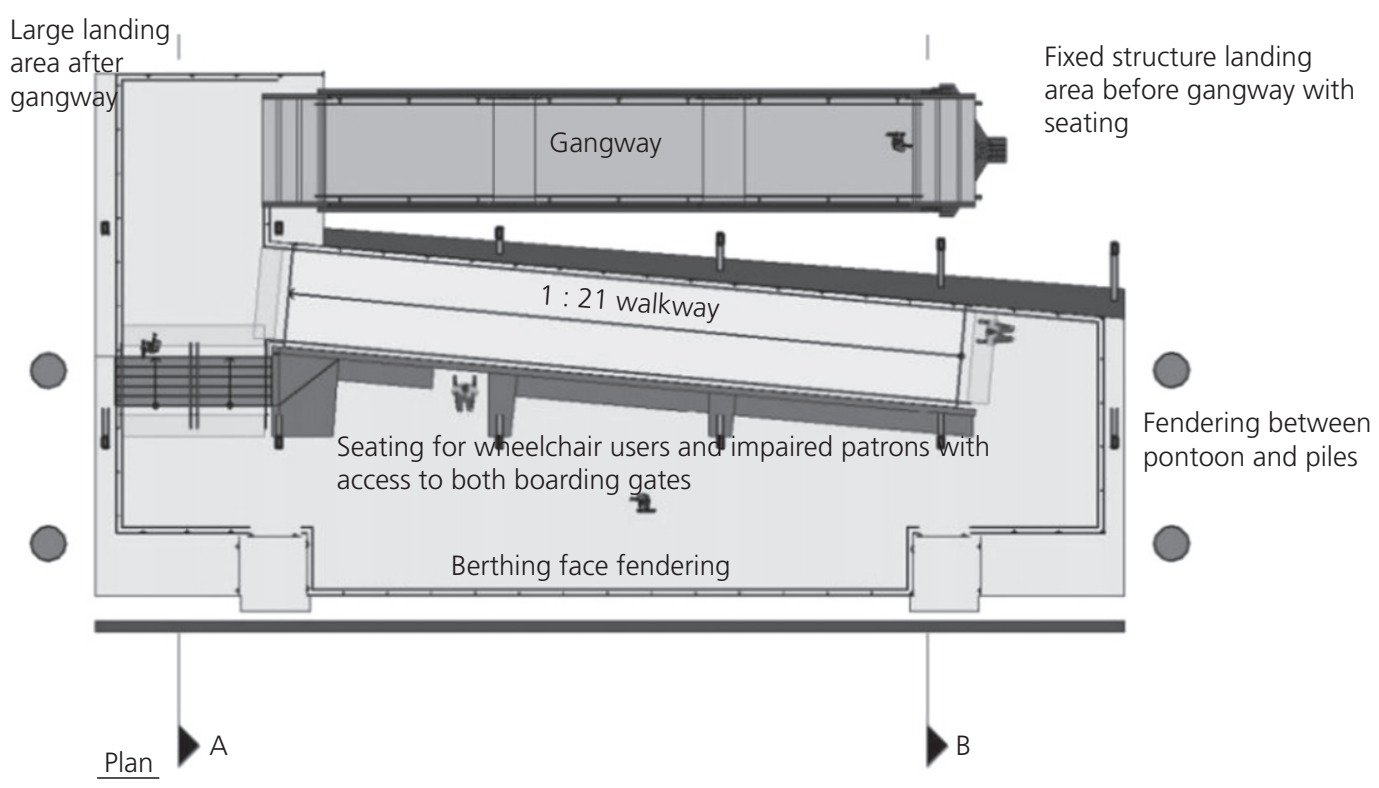

Figure 7. Terminal configuration 
move up and down, roll and/or pitch, resulting in an unstable platform for those waiting on the pontoon.

Providing a sufficient waiting area for patrons on the pontoon was considered a key requirement as it increased the confidence of mobility- and visually-impaired patrons to utilise the terminal easily and therefore increased the likelihood that this group of patrons would make greater use of the transport infrastructure.

However, the provision of a waiting area on the pontoon meant that these patrons would be exposed to the movements of the pontoon. No guidance was specifically available regarding floating structures for the rates of acceleration or velocity changes; therefore, guidance was sought from design guidelines for escalators, which identified maximum values of

\section{- $2.5 \mathrm{~m} / \mathrm{s}^{2}$ for acceleration and \\ - $0.7 \mathrm{~m} / \mathrm{s}$ for velocity.}

Patrons on the pontoon during berthing are anticipating standing on a stable structure, as opposed to those on vessels who understand they are on a moving vehicle. As such, when the vessel berths, if the horizontal acceleration of the pontoon exceeds $2.5 \mathrm{~m} / \mathrm{s}^{2}$ acceleration or $0.7 \mathrm{~m} / \mathrm{s}$ velocity, some patrons may become disorientated and unstable under foot. Provision can be made to provide seating or prevent waiting on the pontoon; however, best practice would be to provide a structure that does not accelerate beyond these defined thresholds by carefully assessing the pontoon fendering arrangement.

For the design of the terminals, a dual-fendering system was employed to minimise the horizontal acceleration and motion of the pontoon. A series of fenders was located along the berthing face and a secondary set of fenders was located between the pontoon and the restraints. This meant that a vessel's motion is initially slowed by the berthing face fendering system, then slowed further by the requirement to mobilise the mass of the pontoon, followed by the pontoon to pile restraint fendering.

The additional size of the pontoon to accommodate the fixed ramp and waiting facilities improved the pontoon's stability against roll and pitch and can be seen in Figure 7.

\section{Lighting}

Minimum lighting levels are provided in AS 1428.1 and AS 1428.2 (SA, 1992, 2009) for access paths (external covered and uncovered, and signs). It was found that elsewhere throughout the terminal, emphasis should be applied to a consistent level of lighting rather than lighting levels.
The original terminals designed in 2000 utilised a series of fluorescent tube lights spaced adequately to achieve the minimum 200 lux for external covered walkways in accordance with AS 1428.1 (SA, 2009) (these requirements are similar to those of BS 5489 (BSI, 2013)).

However, in spacing the lighting out, dark and light areas were generated, causing disorientation to those with visual impairments (Figure 8). The user group also identified that similar disorientation was noted when lights were located beneath the hand railing along walkways.

The design therefore adopted an overhead lighting scheme that utilised multiple low-luminance LED light strips (see Figure 9) that cumulatively provided the minimum lighting level with limited variations across the deck (i.e. without creating dark or bright spots).

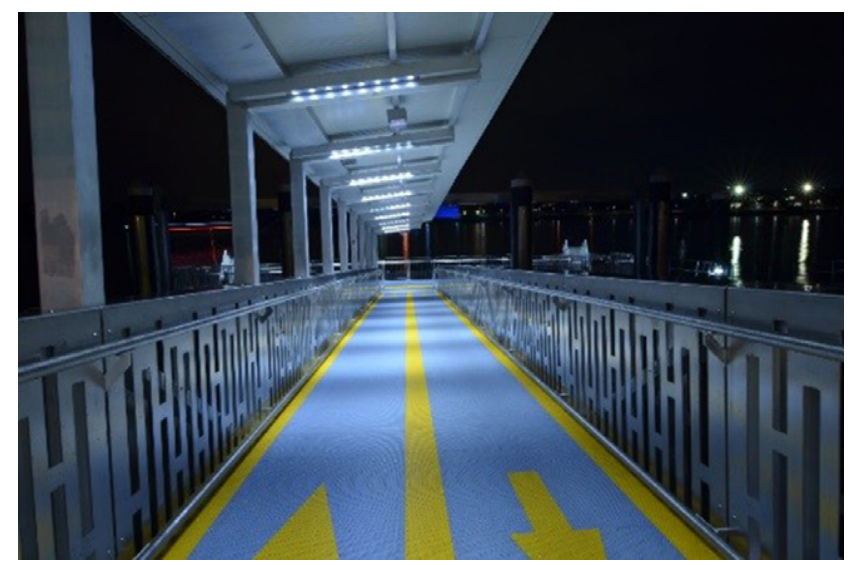

Figure 8. Shadowing from light

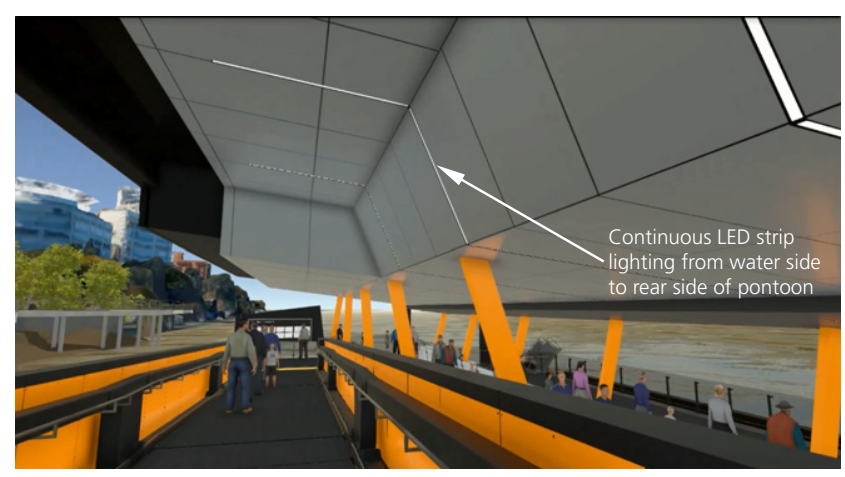

Figure 9. Pontoon lighting configuration 
This also had the added benefit of limiting the number of bright lights that have the potential to create glare on the water and may affect vessel pilots who are utilising the navigation channel.

Another key consideration for lighting is the type of floor material utilised and, in particular, the lighting contrast of the materials selected. For instance, yellow tactile materials on light-grey concrete have a similar light reflective value (LRV) and while the difference in colour is evident to most patrons, the lack of contrast can make it hard for a patron with vision impairments to distinguish the difference.

AS 1428 (SA, 1992, 2009) (BS 8300 in the UK) provides a detailed list of materials and their respective LRVs and advises minimum differences in LRVs for design. Consideration should be given to selecting contrasting elements for flooring, handrails and kick rails, and any embedded signage within the floor (such as edge markings)

\section{Walkway width}

It was found that the major constraint on the access path was double prams (where two seats are provided side by side), which are normally wider than a typical wheelchair. Other constraints were identified as patrons queuing along the access path during peak periods and in sufficient space for passing.

This led to a minimum clear width of $2600 \mathrm{~mm}$ for the access way to allow for a queue line $900 \mathrm{~mm}$ wide, and an access path of $1500 \mathrm{~mm}$ width to allow for a wheelchair and an ambulant person side by side.

At bends in the access path, it was found that bicycles being pushed required the greatest radius for clearance to get around the bends. To allow for a bicycle to be swung around the corner, it was found that a minimum outside radius of $2000 \mathrm{~mm}$ was required.

At the edge of the walkways, the use of a vertical flat plate for kick rails was found to be favoured over a round bar as this provided a surface for white sticks to hit against and removed the risk of the stick becoming jammed at the edge or falling through. It also provided a more consistent surface for pram wheels to be guided by, without the potential for jamming between the deck and the bar.

\section{Virtual reality model/goggles}

To present the information accurately to the client and user group, many of whom who had little or no exposure to viewing two-dimensional (2D) drawings, a 3D model was produced. The model itself was produced from the design Revit file, rendered using a gaming engine and transferred to the relevant files to support a $3 \mathrm{D}$ walkthrough and use of virtual reality goggles (Oculus). Figure 9 shows for a screen capture from the model.

Presenting the file on screen as a $3 \mathrm{D}$ visualisation enabled the client and end users to provide comments regarding the effectiveness of the incorporated design solution at an early stage. One of the elements highlighted from viewing the model was the continuity of the handrails, particularly through the articulation points of the gangway. Modelling software was also utilised to replicate patron access and the formation of queue lines to provide a visual understanding of access path widths. The model also assisted architects in defining and visualising finishes and confirming sight lines through the structure.

The transfer phase between Revit and the 3D model could normally be completed within a day, depending on the level of rendering detail required, which meant that a model could be readily produced after each major design iteration.

\section{Operating ergonomics}

The design of terminals should also consider those who operate them on a daily basis, such as deckhands. Repeated actions such as securing the vessel during mooring, moving and lowering the gangplank into position, and opening and closing the access gates can lead to injuries from fatigue.

Careful consideration should thus be given to the configuration and weight of the access gates to minimise effort to open and close them while deterring the public from unauthorised use. This can be achieved by a gate with a lightweight frame and oversized rollers to decrease the rolling resistance and a latch on the berthing face to minimise access from the pontoon.

The locations of mooring bollards should match those of the vessel cleats that are utilising the terminal. Due to variations between vessel models, a mooring post with two bollards at different heights was provided.

\section{Conclusion}

The UK government has identified that inclusive access for all will have a significant benefit to the population and economy. While clear guidance has evolved for buildings, there are still limitations to applying these requirements to floating structures due to the dynamic motions and variable tide heights. The operation of a terminal also requires conflicting requirements such as minimum lighting levels without glare so as not to impede the navigation channel.

This paper has sought to present some of the design approaches utilised to improve accessibility for a gangway, waiting area, pontoon and lighting, supported by the input of an access consultant and user group. 
In the UK, BS 6349 part 6 (BSI, 2010) is the reference document for the design of structures. However, it does not provide guidance regarding how to design to comply with the requirements stated within BS $8300-1: 2018$. This is likely due to the age of the document, as it was first published in 1989. The document is currently withdrawn for revisions, which provides a good opportunity to address accessibility compliance for floating structures in the newer revision.

\section{Acknowledgements}

The author acknowledges Access Solutions Australia (John Mayo and Wendy Lovelace) for their input for the user group consultation and understanding of the Australian Disability Discrimination Act and DSAPT, and Clay Hickling (GHD) for support during the design phase.

\section{REFERENCES}

Australian Government (2002) Disability Standards for Accessible Transport 2002. The Office of Legislative Drafting and Publishing, Attorney-General's Department, Australian Government, Canberra, Australia.

Australian Government (2014) Disability Discrimination Act 1992. The Office of Parliamentary Counsel, Australian Government, Canberra, Australia.
BSI (2009) BS 8300: Design of buildings and their approaches to meet the needs of disabled people. BSI, London, UK.

BSI (2010) BS 6349: Maritime works series of standards. BSI, London, UK.

BSI (2013) BS 5489: Code of practice for the design of road lighting. Lighting of roads and public amenity areas. BSI, London, UK.

DfT (Department for Transport) (2013) Travel Advisory Leaflet. DfT, London, UK.

Lovelace W (2015) Ferry Terminal Gangway As a Continuous Accessible Path of Travel. Access Solutions Australia, Brisbane, Australia.

Meager N, Evans C, Tackey ND and Williams M (1999) Baseline Survey of the Measures in Part III of the Disability Discrimination Act 1995 Relating to the Provision of Goods and Services. Department of Education and Employment, London, UK.

MHCLG (Ministry of Housing, Communities \& Local Government) (2014) Guidance - Design. MHCLG, Canberra, Australia. See https://www.gov.uk/guidance/design (accessed 10/02/2018).

SA (Standards Australia) (1992) Committee ME-064: Access for People with Disabilities, AS 1428.2 - Design for Access and Mobility Part 2: Enhanced and Additional Requirements - Buildings and Facilities. Australian Standards, Sydney, Australia.

SA (2001) AS 3962: Guidelines for design of marinas. Australian Standards, Sydney, NSW, Australia.

SA (2009) Committee ME-064: Access for People with Disabilities, AS 1428.1: Design for Access and Mobility - Part 1: General Requirements for Access - New Building Work. Australian Standards, Sydney, Australia.

\section{How can you contribute?}

To discuss this paper, please email up to 500 words to the editor at journals@ice.org.uk. Your contribution will be forwarded to the author(s) for a reply and, if considered appropriate by the editorial board, it will be published as discussion in a future issue of the journal.

Proceedings journals rely entirely on contributions from the civil engineering profession (and allied disciplines). Information about how to submit your paper online is available at www.icevirtuallibrary.com/page/authors, where you will also find detailed author guidelines. 